\title{
Speech outcome in tongue cancer surgery: objective evaluation by acoustic analysis software
}

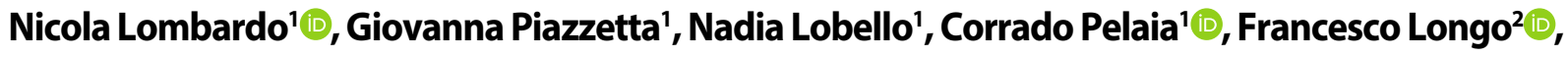

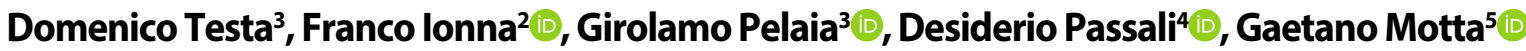 \\ ${ }^{1}$ ENT Unit, Department of Medical and Surgical Sciences, "Magna Græcia” University, Catanzaro, Italy \\ ${ }^{2}$ Melanoma, Soft Tissue, Musculoskeletal and Head-Neck Department, "Fondazione G. Pascale" National \\ Cancer Institute IRCCS, Napoli, Italy \\ ${ }^{3}$ Department of Health Science, "Magna Græcia” University, Catanzaro, Italy \\ ${ }^{4}$ University of Siena, Siena, Italy \\ ${ }^{5}$ Otorhinolaryngology - Head and Neck Surgery, University of Campania "Luigi Vanvitelli”, Napoli, Italy
}

\begin{abstract}
BACKGROUND. Cancer of the oral cavity is one of the most common malignancies of which $60 \%$ affect the tongue. Carcinoma of the tongue causes significant alterations of the articulatory and swallowing functions. The gold standard of care remains primary surgical resection with or without postoperative adjuvant therapy. Whereas T1 and T2 tongue tumors can be treated with more conservative surgeries, as partial glossectomies, the larger tumors require total and aggressive glossectomies which increase survival, but, on the other hand, they might often make speech, chewing and swallowing impossible.

MATERIAL AND METHODS. Our study was performed on a total of 21 patients with Squamous Cell Carcinoma of the tongue who underwent either partial resection or hemiglossectomy. Each subject (either surgical patients or controls) was asked to pronounce the vowels $/ \mathrm{a} /, / \mathrm{e} / \mathrm{,} / \mathrm{i} /, / \mathrm{u} /$, and all signals were evaluated separately by two operators. Acoustic (F0, jitter, shimmer, NHR) and vowel metric (the ratio F2i/F2u, tVSA, qVSA, FCR) features have been extracted. In order to define the speech intelligibility, all patients were evaluated by two doctors and one speech therapist and all patients received the Speech Handicap Index (SHI) translated into Italian language before recording.

RESULTS. No statistically significant variations were observed, regardless of the gender, between controls and surgically resected patients when tumor staging was T1-T2. On the contrary, when patients had to undergo more extensive surgical resection due to the presence of a T3-T4 tumor, a dramatic increase of F2u could be observed. This change, together with a decrease of F2i, led to a highly significant reduction in the F2i/F2u parameter in surgically resected patients as compared to controls. The other parameters which were reduced in a statistically significant manner in T3-T4 surgically resected patients were tVSA and qVSA. Instead, two parameters increased in a statistically significant manner in T3-T4 surgically resected patients: FCR and SHI. Again, none of the above-mentioned parameters was altered in a statistically significant manner in early tumor stage resected patients, regardless of the gender.

CONCLUSION. For the first time, we used a series of newly developed formant parameters, introduced by various authors for the study of the articulatory undershoot of the tongue in various neurodegenerative diseases. The statistical analysis of our results highlighted in an incontrovertible way a strong correlation and significance of each of our parameters F2 / i / / F2 / u /, FCR, tVSA, qVSA, with the entity of the TNM, and therefore of the surgical extension of the resection, and in parallel with the loss of the intelligibility of the speech that proportionally reaches higher values in the advanced stages of the disease as can be deduced from the SHI trend.
\end{abstract}

KEYWORDS: tongue cancer, objective evaluation, vocal signal analysis, acoustic analysis software.

Corresponding author: Nicola Lombardo, Prof., Università Magna Graecia di Catanzaro, Viale Europa, 88100 Catanzaro, Italy ORCID: https://orcid.org/0000-0003-4479-399X

e-mail: nlombardo@unicz.it

Received for publication: September 22, 2021 / Accepted: September 30, 2021 


\section{INTRODUCTION}

Cancer of the oral cavity is one of the most common malignancies, especially in developing countries $^{1}$. Of these neoplasms, $60 \%$ affect the tongue. Early diagnosis is relatively easy, but the presentation with an advanced disease is not uncommon and standard of care remains primary surgical resection with or without postoperative adjuvant therapy. Over the past decade, different improvements in surgical techniques have resulted in improved survival statistics. However, whereas T1 and T2 tongue tumors can be treated with more conservative surgeries as partial glossectomies, the larger tumors (T3 and T4) require total and aggressive glossectomies ${ }^{2,3}$ which increase survival, but, on the other hand, they might often make speech, chewing and swallowing impossible ${ }^{4}$. A variety of premalignant lesions have been associated with the development of squamous cell carcinoma $(\mathrm{SCC})^{5}$. The more common premalignant lesions including leukoplakia, erythroplakia, oral lichen planus and oral submucous fibrosis have varying potential for malignant transformation ${ }^{6,7}$.

Oral cancer is more common in men and usually occurs after the 5 th decade of life. About $1.5 \%$ will have another synchronous primary cancer in the oral cavity or the aerodigestive tract (larynx, esophagus or lung). Oral cancer patients have a high risk of locoregional recurrence and developing subsequent new primary cancers, but the risk of distant recurrence is low $^{8}$. Control of lifestyle-related risk factors, such as tobacco and alcohol consumption, is a priority in these patients because of the higher risk of treatment failure and second primaries ${ }^{9}$. Unfortunately, there is no effective chemoprevention and close follow-up remains the most important tool in secondary prevention ${ }^{10,11}$. A decreased incidence of oral cavity cancer has been reported in the last 15 years, widely attributed to a reduction in tobacco use $\mathrm{e}^{12}$.

In particular, carcinoma of the tongue causes significant alterations of the articulatory and swallowing functions. Tongue resection surgeries involve an alteration of the intelligibility of speech and these compromise communicative-relational abilities and therefore affect the quality of life of these persons ${ }^{13,14}$. However, patients undergoing a glossectomy can develop acceptable intelligibility of speech as a function of several factors, including tumor entity, the extent of surgical resection and the possible involvement of the tip of the tongue. Better intelligibility is achieved for smaller and lateral resections, and it has been shown that flaps reconstruction often causes a worsening of speech intelligibility as a result of scarring that restricts tongue articulatory dynamics. Moreover, rehabilitative intervention allows many patients to achieve good intelligibility speech through compensatory mechanisms at labial, mandibular and pharyngeal levels ${ }^{15,16}$. A good vowel quality depends on the first two formants, F1 that is related to mouth opening and F2 that is dependent on the anteroposterior movement of the tongue ${ }^{17}$. Both formant values are altered by the surgical procedure. The utilization of an F1- F2 chart has evidenced modifications after glossectomy and mandibulectomy, as well as formant shift on the vowels average frequency ${ }^{18,19}$. In the literature, several authors have reported changes in formant values as a consequence of more or less extensive resections of the tongue ${ }^{13-20}$. On the other hand, speech intelligibility alterations are present in various neurodegenerative diseases in which the involvement of the lingual musculature results in an alteration of the articulatory dynamics and consequently in a modification of the phonatory joint, resonance and chewing ${ }^{21-28}$. The study of speech intelligibility is generally carried out by administering questionnaires interpreted by doctors or speech therapists with the aim of defining their impairment on a numerical scale. The anatomical modifications induced by surgery must necessarily determine variations of the formative values as reported in the literature, but the evaluation of how the articulatory dynamics of the language impact on vowel production and define its behaviour in the buccal space has not been the subject of attention in scientific research ${ }^{29-33}$.

The vocal spectrography, that is the electroacoustic analysis of the vocal signal, allows to define the intelligibility of the speech that can be modified even in a normal subject on the basis of the communicative intentionality of the subject, the circumstance of the speech and a series of mood modifications of the patient. Therefore, defining the changes in spectrographic parameters in a sample of speech after surgery of the tongue can allow us to study the modalities of the phonatory compensation implemented by the subject in order to ensure adequate language intelligibility. The reduction of the articulatory dynamics of the postsurgical antero-posterior or inferior superior language compromises the formative values of the F2 / u / and F2 / i / e of the vowel space area and this could constitute a reference of the articulatory and resonance physiology of the non-tongue still described in literature. On the other hand, evaluating behaviours of the lingual, pharyngeal and mandibular residual muscle groups involved allows us to define the preserved intelligibility of speech in the early stages of tongue cancer and its dramatic fall in the advanced stages of the disease ${ }^{34-36}$. 
Table 1. Description of the population.

\begin{tabular}{ccccc}
\hline & Males & Females & Male ctr & Female ctr \\
\hline Total 21 & 15 & 6 & 15 & 6 \\
\hline Radiatio Therapy & 2 & - & - & 68,04 \\
\hline Average age & 64,06 & 69,16 & 65 \\
\hline Median & 68 & 73,5 & 69,8 & 72,6 \\
\hline Maximum age & 79 & 78 & 81 & 79 \\
\hline Minimum age & 33 & 50 & 58 & 61 \\
\hline
\end{tabular}

Table 2. Surgical treatment used.

\begin{tabular}{|c|c|c|}
\hline & Males & Females \\
\hline Partial & $\begin{array}{c}8(3 \mathrm{sx}, \mathrm{Sdx}) \text { of which } 1+\text { front right tonsillar pillar } \\
\text { tonsillectomy + excision }\end{array}$ & 3(2right, 1 left) \\
\hline Hemiglossectom y & 7 (4left,3right) & 3 (1 right,2left) \\
\hline Hemiglossectom y + Mandibulectomia + Flap & 3(2right, 1 left) & \\
\hline
\end{tabular}

The electroacoustic analysis of the vocal production of these subjects can represent an objective tool for setting the rehabilitation treatment and evaluating the results of speech therapy rehabilitation. Defining which of the different acoustic parameters can represent the most useful and valid one from the point of view of statistical significance is the object of our research.

\section{AIMS}

Our study aimed to analyse the formant changes in subjects undergoing partial glossectomy and hemiglossectomy.

\section{MATERIAL AND METHODS}

Our study was performed on a total of 21 patients with Squamous Cell Carcinoma of the tongue who underwent either partial resection or hemiglossectomy between 2001 and 2014 and who were recruited at the "Pascale" Cancer Institute of $\mathrm{Na}$ ples and the University Hospital of Catanzaro during the regular follow-up of patients. Of these, 15 were males and 6 females, mean age for male 64.06 years old (minimum age 33 years old; maximum age 79 years old) and females 69.16 years old (minimum age 50 years old; age 78 years old) (Table 1 ). 7 of the 15 male patients underwent hemiglossectomy (4 left and 3 right), in particular 3 out of 7 underwent also mandibulectomy and preparation of a flap (2 right and 1 left) while the remaining 8 patients experienced a partial resection of the tongue (3 left and 5 right, one of which was simultaneously subjected to tonsillectomy and excision of the anterior tonsillar pillar). As for the female population, 3 were subjected to hemiglossectomy (1 right and 2 left) and 3 to tongue partial resection (2 right and 1 left). All patients were treated for primary disease (Table 2). Selective neck dissection was performed in all patients $(6 / 21)$ with $\mathrm{N}>0$ and in T3-T4 regardless of $\mathrm{N}$.

Histological lymph node-positive patients who fulfilled the requirements of radiation therapy 
Table 3. Summary of TNM staging.

\begin{tabular}{ccc}
\hline & Males & Females \\
\hline Histological type & $\begin{array}{c}4 \text { poorly differentiated } \\
11 \text { moderately differentiated }\end{array}$ & 6 moderately differentiated \\
\hline T1NOMO & 4 & 1 \\
\hline T2NOMO & 5 & 5 \\
\hline T3NOMO & 2 & \\
\hline T3N1M0 & 1 & \\
\hline T3N2MO & 1 & \\
\hline TLNOMO & 1 & \\
\hline TLN1MO & 1 & \\
\hline
\end{tabular}

were sent for treatment about a month after surgery. From the time of diagnosis, surgery and radiotherapy, the minimum period which elapsed since the evaluation was not shorter than three years. Histological examination of the sample documented the presence of poorly differentiated Squamous Cell Carcinoma in 4 of 15 males, the other 11 males and the 6 female patients were suffering from moderately differentiated Squamous Cell Carcinoma. Splitting our sample according to the TNM classification, we have: for the female patients, 1 T1N0M0 and 5 T2N0M0; the male population can be classified as 4 T1N0M0, 5 T2N0M0, 2 T3N0M0, 1 T3N1M0, 1 T3N2M0, 1 T4N0M0, 1 T4N1M0. In turn, the entire sample was grouped by gender and for the sake of staging ( 6 women with carcinoma of the tongue T1-T2N0M0, 9 T1-T2 and 6 males T3 or T4). Patients' classification as a function of TMN staging is summarized in Table 3.

Digital voice recordings of the subjects were made in a room with a background noise around $20 \mathrm{~dB}$ with commercial audio software (Acer Aspire E15-E5-571G) and a dynamic microphone head-set (Shure, model 14A, made in Mexico) located at 10 $\mathrm{cm}$ from the lips, with an inclination of 45 degrees. Each subject (either surgical patients or controls) was asked to pronounce the vowels/a/, /e/, /i/, $/ \mathrm{u} /$, each lasting about 10 seconds. The sample rate was $44,100 \mathrm{~Hz}$ to 16-bit. All acoustic analyses were performed with the Praat software (version 5.2.21 Paul Boersma and David Wennick, March 29, 2011, Institute of phonetic Sciences, University of Amsterdam, Amsterdam, Netherlands. Http:// www.praat.org/) by using the central part of the signal. The assessment was made on the basis of the waveform signal and narrowband analysis. All signals were evaluated separately by two operators. The average value of formant frequencies and standard deviation of each vowel were assessed. In particular, F1 and F2 vowels mean values were estimated averaging five points selected in the middle portion of the vowel; the F1 and F2 vowels mean values determined as described above were used to calculate the ratio F2i/F2u, tVSA, qVSA and FCR. All parameters were stored in a database. In order to define the speech intelligibility, all patients were evaluated by two doctors and one speech therapist on the basis of the recognition of sentences including the months of the year, the numbers from 1 to 10 and a spontaneous phrase pronounced by the patient in which he reported his/her personal data. The scale used by the two doctors and by the speech therapist classified the speech intelligibility as perfectly understandable, poorly understood, incomprehensible. All patients received the Speech Handicap Index (SHI) translated into Italian language before recording. A TMN staging was used to subdivide our sample into four groups: 5 T1N0M0; 10 T2N0M0; 4 T3N(0-2) M0; 2 T4N(0-1)M0. Continuous variables are described as median and range, while those categorical as an absolute and percentage value. Statistical analysis was performed using the Mann-Whitney test, where appropriate. A generalized linear re- 
Table 4. The data of all recorded parameters as a function of tumor $\mathrm{T}$ staging.

\begin{tabular}{|c|c|c|c|c|c|c|}
\hline & T1 & T2 & T3 & T4 & M ctr & F ctr \\
\hline Fo & 151 & 164,425 & 96,514 & 142,75 & 156,14 & 268,3 \\
\hline JITTER & 0,158 & 0,3745 & 0,3285 & 0,224 & 0,1872 & 0,25 \\
\hline SHIMME & 4,806 & 8,7855 & 3,065 & 10,5275 & 4,8714 & 4,23 \\
\hline NHR & 0,009 & 0,0705 & 0,016 & 0,04105 & 0,18 & 0,024 \\
\hline F1a & 728 & 869 & 653 & 765,5 & 776,6 & 939,72 \\
\hline $\mathrm{F} 2 \mathrm{a}$ & 1224 & 1392 & 1240,5 & 1322 & 1332,4 & 1600,3 \\
\hline F1i & 307 & 352 & 287 & 410 & 359,4 & 392,9 \\
\hline $\mathrm{F} 2 \mathrm{i}$ & 2093 & 2066,5 & 1935,5 & 1746 & 2213,4 & 2264,5 \\
\hline $\mathrm{F} 1 \mathrm{u}^{*}$ & 343 & 417,5 & 256 & 419 & 400,6 & 439,3 \\
\hline $\mathrm{F} 2 \mathrm{u}^{*}$ & 989 & 1284,5 & 1384,5 & 1356 & 1255,2 & 1258,54 \\
\hline F1e & 498 & 560 & 388,5 & 609 & 457,8 & 644,1 \\
\hline F2e & 1770 & 1858 & 1916 & 1601,5 & 1971 & 2017,72 \\
\hline $\mathrm{F} 2 \mathrm{i} / \mathrm{F} 2 \mathrm{u}^{*}$ & 2,66 & 1,77 & 1,39 & 1,285 & 2,122 & 2,009 \\
\hline tVSA & 272110,5 & 187761,75 & 109374 & 67238,5 & 208800,6 & 285923,6 \\
\hline qVSA* & 298706 & 197581,75 & 143537,5 & 85207,5 & 201733,6 & 237176,7 \\
\hline$F C R^{* *}$ & 1,672587948 & 1,882962137 & 2,017156 & 2,06596 & 1,8707 & 1,89 \\
\hline TMF & 14,01 & 8,18 & 17,27 & 7,865 & 19 & 16 \\
\hline
\end{tabular}

gression model was used to test the role of TNM staging in the evaluation of the results. In order to calculate the power a posteriori ( $1-\beta$ error at 2 code) of the statistical tests used, we have taken into account the sample size, effect size observed and a $=.05$ error. The statistical results were fully accepted if supported by a power $>80 \%$. IBM SPSS Statistics (version 21.0.0.1, IBM Corp., Armonk,
NY, USA) and G* Power (version 3.1, Institut für Experimentelle Psychologie, Heinrich Heine University, Düsseldorf, FRG) softwares were used for data collection and statistical analyses. P-values < 0.05 were considered statistically significant (code 2). Our sample was divided based on the TNM classification: in Group A (T1-T2 N0M0) and Group B (T3-T4 N (0-2) M0). Each group was divided into 
Table 5. Statistical analysis, performed against age-matched controls.

\begin{tabular}{|c|c|c|c|c|c|}
\hline & Healthy Males & T1-T2 Males & T3-T4 Males & Healthy Females & T1-T2 Females \\
\hline TOT & 15 & 9 & 6 & 11 & 6 \\
\hline $\mathrm{F} 2 \mathrm{i}$ & 2213,4 & 2250,667 & 1883 & 2264,5 & 22210 \\
\hline $\mathrm{F} 2 \mathrm{u}$ & 1255,2 & 1140 & 1519,167 & 1258,54 & 1178,8 \\
\hline $\mathrm{F} 2 \mathrm{i} / \mathrm{F} 2 \mathrm{u}$ & 2,122 & 2,1156 & 1,2716 & 2,009 & 2,005 \\
\hline tVSA & 208800,6 & 214034,9 & 126501,8 & 285923,6 & 281332,3 \\
\hline qVSA & 201733,6 & 224810,2 & 61457,67 & 237176,7 & 243754,7 \\
\hline FCR & 1,8707 & 1,842458 & 2,07115 & 1,89 & 1,88 \\
\hline SHI & $<6$ & 5,00 & 46 & $<6$ & 5,00 \\
\hline
\end{tabular}

one sample of males only and one of females only. While for males it was possible to differentiate the two groups A and B, for females we performed our measurements only for group T1-T2, due to the lack among the enrolled patients of females with advanced disease. Each of these groups was compared with groups of healthy subjects matched by age and sex for which identical measurements were performed. For the male sample the ANOVA test was performed, while for females the t-student test was used.

\section{OUTCOMES AND RESULTS}

The data of all recorded parameters are illustrated in Table 4 as a function of tumor T staging. As described in the Material and methods section, patients were divided based on the TNM classification: in Group A (T1-T2 N0M0) and Group B (T3T4 N (0-2) M0), and the statistical analyses were performed against age-matched controls. The results are summarized in Table 5. Interestingly, no statistically significant variations were observed, regardless of the gender, between controls and surgically resected patients when tumor staging was T1-T2 (Table 5). On the contrary, when patients had to undergo more extensive surgical resection due to the presence of a T3-T4 tumor, a dramatic increase of $F 2 u(p=0.001)$ could be observed. This change, together with a decrease of F2i (although not statistically significant), led to a highly significant $(p=0.003)$ reduction in the F2i/F2u parameter in surgically resected patients as compared to controls (Table 5). The other parameters which were reduced in a statistically significant manner in T3-T4 surgically resected patients were tVSA ( $p$ $=0.037)$ and qVSA $(p=0.038)$. Instead, two parameters increased in a statistically significant manner in T3-T4 surgically resected patients: FCR $(p=0.040)$ and SHI $(p=0.023)$ (Figure 1 and Figure 2 ). Again, none of the above-mentioned parameters was altered in a statistically significant manner in early tumor stage resected patients, regardless of the gender (Table 5).

\section{CONCLUSIONS AND IMPLICATIONS}

Tongue carcinoma surgically treated with partial glossectomy or hemiglossectomy determines alterations of voice intelligibility, which are related to the extent of tumor resection and TNM staging. In fact, we show that serious vocal abnormalities are obtained in Group B (T3-T4) compared with groups A (T1-T2). The most interesting data is that the new parameters, proposed by some authors for the study of articulatory undershoot in neurode- 


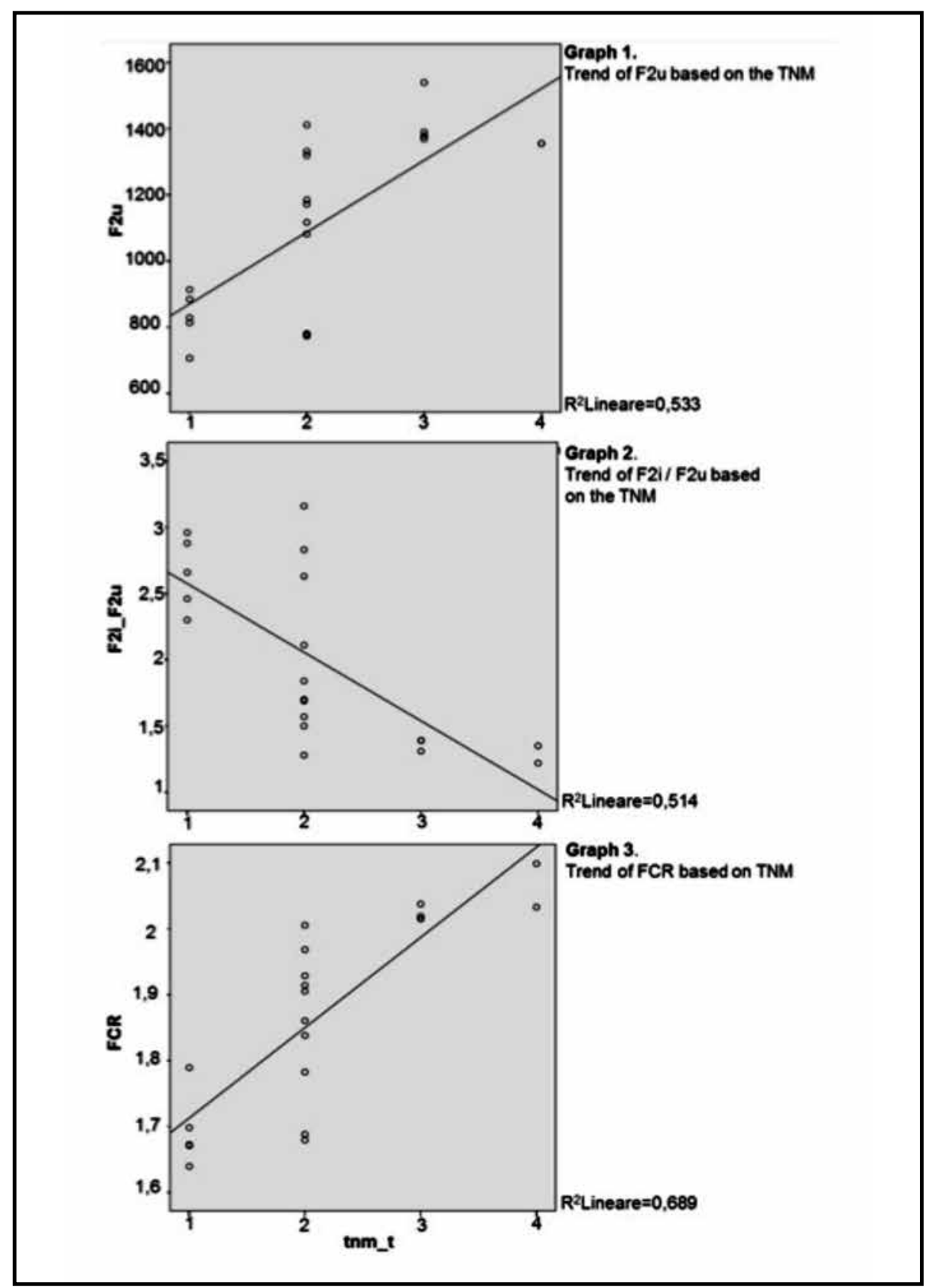

Figure 1. More extensive surgical resection causes a dramatic increase in $F 2 u(p=0.001)$, a decrease in $F 2 i$ (although not statistically significant) and a highly significant $(p=0.003$ ) reduction in the $F 2 i / F 2 u$ parameter.

generative diseases, were introduced by us for the analysis of speech-out in a sample of patients undergoing glossectomy. Here we show that the speech intelligibility, measured on the basis of the score given to a questionnaire filled up by the patient, SHI is perfectly normal in T1-T2 both male and female, while it is significantly altered in T3T4. It is worthy of notice that the mere study of formants values, proposed in the past literature, does not detect the mechanisms of compensation that are at the basis of the good speech intelligibil- ity reached by these subjects. In fact, the analysis of the tVSA, but especially qVSA, demonstrates a dramatic decline in subjects of the Group T3-T4, which correlates with the alterations observed for SHI (Table 5); this is a strong indication of the usefulness of the tVSA and, especially, of the qVSA as objective parameters for defining the speech intelligibility. On the other hand, the simple study of formants values that are altered in the early stages of the disease does not result, as is known, in the modification of the intelligibility of speech. We 


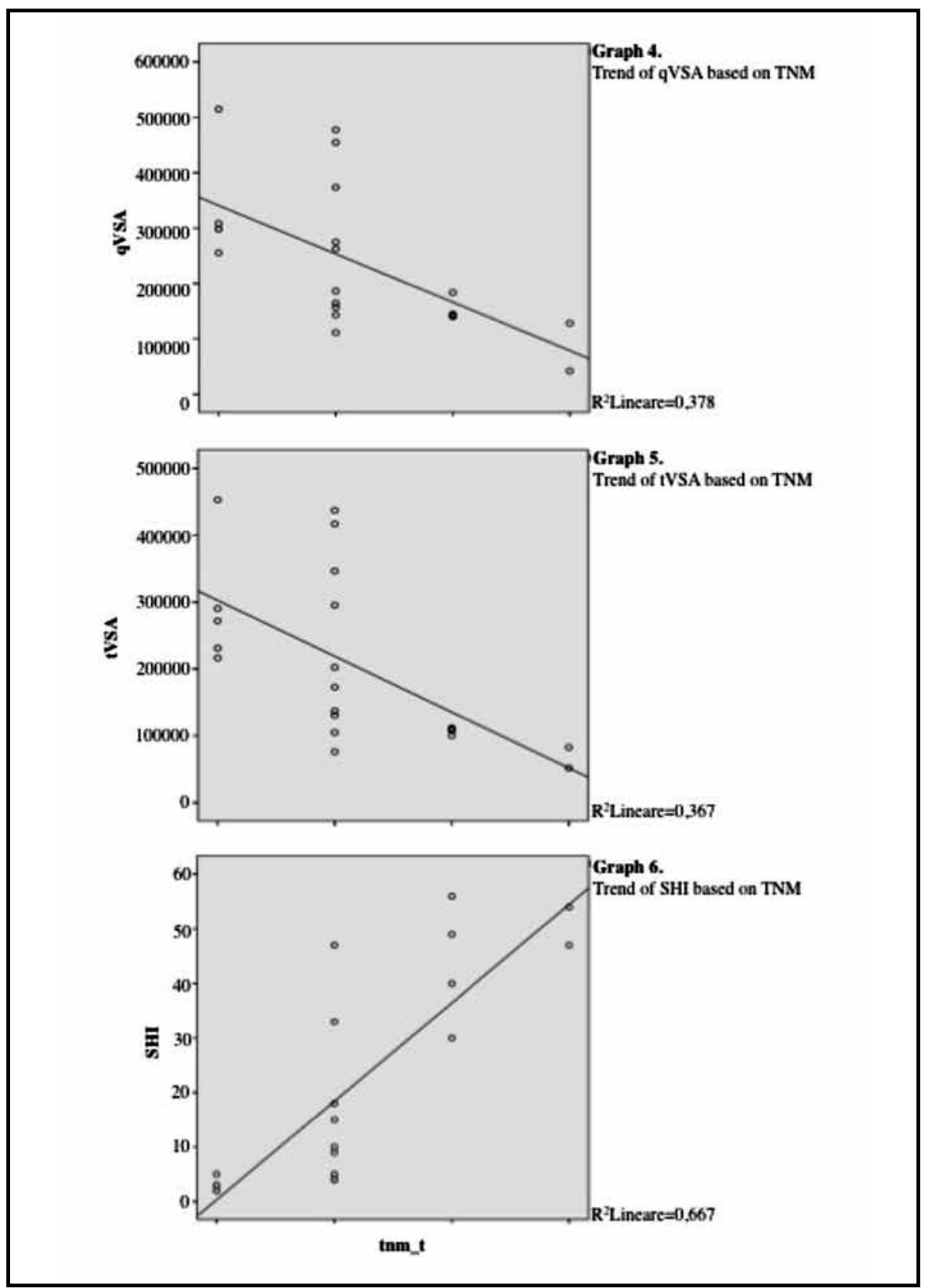

Figure 2. The other parameters which were reduced in a statistically significant manner in T3-T4 surgically resected patients were tVSA $(p=0.037)$ and qVSA $(p=0.038)$. Two parameters that increased in a statistically significant manner in T3-T4 surgically resected patients are FCR $(p=0.040)$ and $S H I(p=0.023)$.

confirmed previous data, measuring changes of F2 /i/ and / F2 / u/ values, which in T1-T2 has a shift in the location of formants on the chart F1-F2 without the local volumetric changed, so you do not see the centralization of formants as demonstrated by the steadiness of FCR. Moving then to the right formants' values of $\mathrm{F} 2 / \mathrm{i} /$ and $\mathrm{F} 2 / \mathrm{u} /$, without alteration of their relationship, testifies in T1-T2 both males and females the invariance of FCR and the VSA.

It is documented, with parametric evaluation, the compensation which the patient puts in place to improve the intelligibility of speech and make virtually nil small changes of formants which are also present. Our study aimed to analyse the formant changes in subjects undergoing partial glossectomy and hemiglossectomy. As reported in literature, the analysis of the median values of the various formants of the four corner vowels highlights the alterations of these and in particular of the F2 / i / . For the first time in the literature, we used a series of newly developed formant parame- 
ters, introduced by various authors for the study of the articulatory undershoot of the tongue in various neurodegenerative diseases ${ }^{35}$. The statistical analysis of our results highlighted, in an incontrovertible way, a strong correlation and significance of each of our parameters F2 / i / / F2 / u /, FCR, tVSA, qVSA, with the entity of the TNM, and therefore of the surgical extension of the resection, and in parallel with the loss of the intelligibility of the speech that proportionally reaches higher values in the advanced stages of the disease, as can be deduced from the SHI trend.

Conflict of interest: The authors have no conflict of interest.

Contribution of authors: N. Lombardo conceived and planned the study. G. Piazzetta, C. Pelaia, F. Longo carried out the work. D. Testa, F. Ionna, G. Pelaia, D. Passali and G. Motta contributed to the interpretation of the results. N. Lombardo and N. Lobello took the lead in writing the manuscript. All authors provided critical feedback and helped shape the research, analysis and manuscript. All authors read and approved the final version of the manuscript.

\section{REFERENCES}

1. Siegel R, Naishadham D, Jemal A. Cancer statistics, 2013. CA Cancer J Clin. 2013;63(1):11-30. DOI: 10.3322/caac.21166.

2. Righini S, Festa BM, Bonanno MC, Colombo V, Luca N. Dynamic tongue reconstruction with innervated gracilis musculocutaneos flap after total glossectomy. Laryngoscope. 2019;129(1):76-81. DOI: 10.1002/lary.27176.

3. Omura K. Current status of oral cancer treatment strategies: surgical treatments for oral squamous cell carcinoma. Int J Clin Oncol. 2014;19(3):423-30. DOI: 10.1007/s10147-014-0689-z.

4. Dziegielewski PT, Ho ML, Rieger J, Singh P, Langille M, Harris JR, et al. Total glossectomy with laryngeal preservation and free flap reconstruction: objective functional outcomes and systematic review of the literature. Laryngoscope. 2013;123(1):140-5. DOI: 10.1002/ lary. 23505 .

5. Montero PH, Patel SG. Cancer of the oral cavity. Surg Oncol Clin N Am. 2015;24(3):491-508. DOI: 10.1016/j.soc.2015.03.006

6. Warnakulasuriya S, Johnson NW, van der Waal I. Nomenclature and classification of potentially malignant disorders of the oral mucosa. J Oral Pathol Med. 2007;36(10):575-80. DOI: 10.1111/j.1600-0714.2007.00582.x.

7. Neville BW, Day TA. Oral cancer and precancerous lesions. CA Cancer J Clin. 2002;52(4):195-215. DOI: 10.3322/canjclin.52.4.195.

8. Lin K, Patel SG, Chu PY, Matsuo JM, Singh B, Wong RJ, et al. Second primary malignancy of the aerodigestive tract in patients treated for cancer of the oral cavity and larynx. Head Neck. 2005;27(12):1042-8. DOI: 10.1002/hed.20272.

9. Silverman S Jr, Rankin KV. Oral and pharyngeal cancer control through continuing education. J Cancer Educ. 2010;25(3):277-8. DOI: $10.1007 / \mathrm{s} 13187-010-0044-7$.

10. Foy JP, Bertolus C, William WN Jr, Saintigny P. Oral premalignancy: the roles of early detection and chemoprevention. Otolaryngol Clin North Am. 2013;46(4):579-97. DOI: 10.1016/j.otc.2013.04.010.

11. Chen YK, Huang HC, Lin LM, Linn CC. Primary oral squamous cell carcinoma: an analysis of 703 cases in southern Taiwan. Oral Oncol. 1999;35(2):173-9. DOI: 10.106/s1368-8375(98)00101-8.

12. Howlader N, Noone AM, Krapcho M, Neyman N, Aminou R, Waldron W, et al. SEER Cancer Statistics Review, 1975-2008. National Cancer Institute. Bethesda, MD, based on November 2010 SEER data submission, posted to the SEER web site, 2011. [Internet]. Available from: https://seer.cancer.gov/archive/csr/1975_2008/.

13. Kazi R, Prasad VMN, Kanagalingam J, Georgalas C, Venkitaraman R, Nutting CM, et al. Analysis of formant frequencies in patients with oral or oropharyngeal cancers treated by glossectomy. Int J Lang Commun Disord. 2007;42(5):521-32. DOI: 10.1080/13682820601056566.

14. Matsui Y, Ohno K, Yamashita Y, Takahashi K. Factors influencing postoperative speech function of tongue cancer patients following reconstruction with fasciocutaneous/myocutaneous flaps-a multicenter study. Int J Oral Maxillofac Surg. 2007;36(7):601-9. DOI: 10.106/j.ijom.2007.01.014.

15. Sasahira T, Kirita T, Kuniyasu H. Update of molecular pathobiology in oral cancer: a review. Int J Clin Oncol. 2014;19(3):431-6. DOI: 10.1007/s10147-014-0684-4.

16. Guha N, Boffetta P, Wünsch Filho V, Eluf Neto J, Shangina O, Zaridze D, et al. Oral health and risk of squamous cell carcinoma of the head and neck and esophagus: results of two multicentric casecontrol studies. Am J Epidemiol. 2007;166(10):1159-73. DOI: 10.1039/aje/kwm193.

17. Harrison LB, Sessions RB, Hong WK. Head and Neck Cancer: A Multidisciplinary Approach. 3rd edition. Philadelphia, PA: Lippincott, William and Wilkins; 2009.

18. Knuuttila H, Pukander J, Maatta T, Pakarinen L, Vilkman E. Speech articulation after subtotal glossectomy and reconstruction with a myocutaneous flap. Acta Otolarynogol. 1999;119(5):621-6. DOI: $10.1080 / 00016489950180892$

19. LaRiviere C, Seilo MT, Dimmick KC. Report on the speech intelligibility of a glossectomee: perceptual and acoustic observations. Folia Phoniatr. 1975;27(3):210-4. DOI: 10.1159/000263987.

20. Whitehill T, Ciocca V, Chan JCT, Samman N. Acoustic analysis of vowels following glossectomy. Clinic Linguist Phon. 2006;20(23):135-40. DOI: $10.1080 / 02699200400026694$.

21. Mirarchi D, Vizza P, Tradigo G, Lombardo N, Arabia G, Veltri P. Signal analysis for voice evaluation in Parkinson's disease. [Internet]. Proceedings-IEEE International Conference on Healthcare Informatics (ICHI). 2017;530-5. DOI: 10.1109/ICHI.2017.72. Available from: https://ieeexplore.ieee.org/document/8031207.

22. Tradigo G, Calabrese B, Macrì M, Vocaturo E, Lombardo N, Veltri P. Voice signal features analysis and classification: looking for new diseases related parameters. [Internet]. Proceedings of the 6th ACM Conference on Bioinformatics, Computational Biology and Health Informatics. 2015;589-96. DOI: 10.1145/2808719.2812222. Available from: https://www.semanticscholar.org/paper/Voice-signal-features-analysis-and-classification \% 3A-Tradigo-Calabrese/f66f17b0a88680c459939ffdfbcf42b42716434e.

23. Vizza P, Tradigo G, Mirarchi D, Bossio B, Lombardo N, Arabia G, et al. Methodologies of speech analysis for neurodegenerative diseases evaluation. Int J Med Inform. 2019;122:45-54. DOI: 10.1016/j.ijmedinf.2018.11.008

24. Turner G, Tjaden K, Weismer G. The influence of speaking rate on vowel space and speech intelligibility for individuals with amyotrophic lateral sclerosis. J Speech Hear Res. 1995:38(5):1001-13. DOI: $10.1044 /$ jshr.3805.1001. 
25. Weismer G, Jeng JY, Laures JS, Kent RD, Kent JF. Acoustic and intelligibility characteristics of sentence production in neurogenic speech disorders. Folia Phoniatr Logop. 2001;53(1):1-18. DOI: 10.1159/000052649.

26. Tjaden K, Wilding GE. Rate and loudness manipulations in dysarthria: acoustic and perceptual findings. J Speech Lang Hear Res. 2004;47(4):766-83. DOI: 10.1044/1092-4388(2004/058).

27. Sapir S, Spielman JL, Ramig LO, Story BH, Fox C. Effects of intensive voice treatment (the Lee Silverman Voice Treatment [LSVT]) on vowel articulation in dysarthric individuals with idiopathic Parkinson disease: acoustic and perceptual findings. J Speech Lang Hear Res. 2007;50(4):899-912. DOI: 10.1044/1092-4388(2007/064).

28. Sapir S, Ramig LO, Spielman JL, Fox C. Formant centralization ratio (FCR): A proposal for new acoustic measure of dysarthric speech. J Speech Lang Hear Res. 2010;53(1):114. DOI: 10.1044/10924388(2009/08-0184).

29. Roy N, Nissen SL, Dromey C, Sapir S. Articulatory changes in muscle tension dysphonia: evidence of vowel space expansion following manual circumlaryngeal therapy. J Commun Disord. 2009;42(2):12435. DOI: 10.106/j.jcomdis.2008.10.001.

30. Skodda S, Visser W, Schlegel U. Vowel articulation in Parkinson's disease. J Voice. 2011;25(4):467-72. DOI: 10.1016/j.jvoice.2010.01.009.

31. Rinkel RN, Verdonck-de Leeuw IM, van Reij EJ, Aaronson NK, Leemans CR. Speech Handicap Index in patients with oral and pharyn- geal cancer: better understanding of patients' complaints. Head Neck. 2008;30(7):868-74. DOI: 10.1002/hed.20795.

32. Palumbo A, Calabrese B, Vizza P, Lombardo N, Garozzo A, Cannataro M, et al. A novel portable device for laryngeal pathologies analysis and classification. Lecture Notes Electr Eng. 2010;55:335-52.

33. Palumbo A, Amato F, Calabrese B, Cannataro M, Veltri P, Garozzo A, et al. A novel portable device for pathological voice analysis. [Internet]. IEEE International Workshop on Medical Measurements and Applications, MeMeA. 2005;1:51-4. DOI: 10.1109/ MEMEA.2009.5167953. Available from: https://info.computer.org/ csdl/proceedings-article/memea/2009/05167953/12OmNxH9Xe3.

34. Palumbo A, Veltri P, Cannataro M, Vizza P, Calabrese B. Experiences of using a DSP based device for vocal signal analysis. [Internet]. 7th International Workshop on Models and Analysis of Vocal Emissions for Biomedical Applications, MAVEBA. 2011;187-9. Available from: https://www.torrossa.com/es/resources/an/2469247.

35. Lombardo N, Lobello N, Piazzetta G, Ciriolo M, Pelaia P, Testa D, et al. Intrinsic laryngeal lipoma treated with transoral CO2 Laser microsurgery: an unusual case report. Am J Case Rep. 2020;21:e920528-1-e920528-5. DOI: 10.12659/AJCR.920528.

36. Lombardo N, Aragona T, Alsayyad S, Pelaia G, Terracciano R, Savino R. Objective and self-evaluation voice analysis after transoral laser cordectomy and radiotherapy in T1a-T1b glottic cancer. Lasers Med Sci. 2018;33(1):141-7. DOI: 10.1007/s10103-017-2361-0.

This is an open access article published under the terms and conditions of the Creative Commons Attribution-NonCommercial-NoDerivatives 4.0 International (CC BY-NC-ND 4.0) License (https://creativecommons.org/licenses/by-nc-nd/4.0/). CC BY-NC-ND 4.0 license requires that reusers give credit to the creator by citing or quoting the original work. It allows reusers to copy, share, read, download, print, redistribute the material in any medium or format, or to link to the full texts of the articles, for non-commercial purposes only. If others remix, adapt, or build upon the material, they may not distribute the modified material. 